\title{
NASA LaRC airborne high spectral resolution lidar aerosol measurements during MILAGRO: observations and validation
}

\author{
R. R. Rogers ${ }^{1}$, J. W. Hair ${ }^{1}$, C. A. Hostetler ${ }^{1}$, R. A. Ferrare ${ }^{1}$, M. D. Obland ${ }^{1}$, A. L. Cook $^{1}$, D. B. Harper ${ }^{1}$, S. P. Burton ${ }^{2}$, \\ Y. Shinozuka ${ }^{3,5}$, C. S. McNaughton ${ }^{3}$, A. D. Clarke ${ }^{3}$, J. Redemann ${ }^{4}$, P. B. RusselI ${ }^{5}$, J. M. Livingston ${ }^{6}$, and \\ L. I. Kleinman ${ }^{7}$ \\ ${ }^{1}$ NASA Langley Research Center, Hampton, VA, USA \\ ${ }^{2}$ SSAI/NASA Langley Research Center, Hampton, VA, USA \\ ${ }^{3}$ University of Hawaii, Dept. of Oceanography, Honolulu, HI, USA \\ ${ }^{4}$ BAERI/NASA Ames Research Center, Moffett Field, CA, USA \\ ${ }^{5}$ NASA Ames Research Center, Moffett Field, CA, USA \\ ${ }^{6}$ SRI International/NASA Ames Research Center, Moffett Field, CA, USA \\ ${ }^{7}$ Brookhaven National Laboratory, Upton, NY, USA
}

Received: 11 March 2009 - Published in Atmos. Chem. Phys. Discuss.: 2 April 2009

Revised: 30 June 2009 - Accepted: 9 July 2009 - Published: 22 July 2009

\begin{abstract}
The NASA Langley Research Center (LaRC) airborne High Spectral Resolution Lidar (HSRL) measures vertical profiles of aerosol extinction, backscatter, and depolarization at both $532 \mathrm{~nm}$ and $1064 \mathrm{~nm}$. In March of 2006 the HSRL participated in the Megacity Initiative: Local and Global Research Observations (MILAGRO) campaign along with several other suites of instruments deployed on both aircraft and ground based platforms. This paper presents high spatial and vertical resolution HSRL measurements of aerosol extinction and optical depth from MILAGRO and comparisons of those measurements with similar measurements from other sensors and model predictions. HSRL measurements coincident with airborne in situ aerosol scattering and absorption measurements from two different instrument suites on the C-130 and G-1 aircraft, airborne aerosol optical depth (AOD) and extinction measurements from an airborne tracking sunphotometer on the J-31 aircraft, and AOD from a network of ground based Aerosol Robotic Network (AERONET) sun photometers are presented as a validation of the HSRL aerosol extinction and optical depth products. Regarding the extinction validation, we find bias differences between HSRL and these instruments to be less than 3\% $\left(0.01 \mathrm{~km}^{-1}\right)$ at $532 \mathrm{~nm}$, the wavelength at which the HSRL technique is employed. The rms differences at $532 \mathrm{~nm}$ were less than $50 \%\left(0.015 \mathrm{~km}^{-1}\right)$. To our knowledge this is the
\end{abstract}

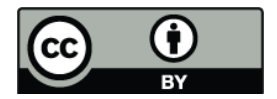

Correspondence to: R. R. Rogers (raymond.r.rogers@nasa.gov) most comprehensive validation of the HSRL measurement of aerosol extinction and optical depth to date. The observed bias differences in ambient aerosol extinction between HSRL and other measurements is within $15-20 \%$ at visible wavelengths, found by previous studies to be the differences observed with current state-of-the-art instrumentation (Schmid et al., 2006).

\section{Introduction}

Tropospheric aerosols influence the radiative budget of the earth directly by scattering and absorbing solar radiation and indirectly by serving as cloud condensation nuclei. When attempting to account for direct and indirect aerosol radiative effects on climate change, the Intergovernmental Panel on Climate Change concluded that the uncertainties associated with aerosol radiative forcings were larger than the uncertainties associated with any of the other principal components of radiative forcing impacting climate change (Solomon et al., 2007). Aerosols have highly variable optical and physical properties, relatively short atmospheric lifetimes, and large spatial and temporal gradients; these factors complicate efforts to account for their radiative forcing impacts in climate models. Another key component directly affecting the radiative forcing is the aerosol vertical profile (e.g. Haywood et al., 1997). Indeed, Satheesh (2002) found that the aerosol radiative forcing can differ significantly for identical aerosol

Published by Copernicus Publications on behalf of the European Geosciences Union. 
layers located at different altitudes; it is therefore important to have an accurate measurement of aerosol optical properties and vertical profile measurements. In addition to improving estimates of aerosol radiative forcing, knowledge of the vertical profile of aerosol is useful for augmenting the retrieval of aerosol properties from satellite-based passive radiometric instruments, such as aerosol absorption (Torres et al., 1998).

Lidar is an excellent technique to measure the vertical profile of aerosol optical properties, offering both high vertical resolution and high temporal resolution. Deployed from aircraft, lidars are capable of mapping vertical distributions of aerosol over large spatial regions in a relatively short amount of time - something that is not possible with in-situ instruments. Unlike the standard elastic backscatter technique, the High Spectral Resolution Lidar (HSRL) technique accurately measures the vertical profile of aerosol extinction without reliance on an external measurement of aerosol optical depth (AOD) (McGill et al., 2003) or assumptions of the aerosol extinction-to-backscatter ratio (Hair et al., 2001, 2008; Cattrall et al., 2005) to constrain the extinction retrieval.

In this paper we present the NASA Langley airborne HSRL measurements from the MILAGRO field campaign (Molina et al., 2009). This campaign was designed to study the evolution of trace gases and aerosols above and downwind of Mexico City and employed ground-based instrumentation in and around the urban megacity along with numerous airborne instruments on seven aircraft. We begin by describing the HSRL data taken during this mission and their usefulness for providing vertical and horizontal context for ground and aircraft based in-situ measurements. The HSRL extinction profile measurements are then validated for the first time via comparisons with three state-of-the-art measurement techniques on board three different aircraft, and the HSRL aerosol optical depth measurements are validated via comparison with airborne and ground based sunphotometer measurements.

\section{HSRL measurements during MILAGRO}

The HSRL was deployed on the NASA LaRC B-200 King Air aircraft, which operated from Veracruz, Mexico, and measured profiles of aerosol extinction, backscatter, and depolarization from a nominal level flight altitude of $8.5 \mathrm{~km}$ (28 kft) during the MILAGRO field campaign in March 2006. The HSRL collected approximately $55 \mathrm{~h}$ of data over 17 science flights during MILAGRO, many of which were coordinated with the NASA J-31 aircraft, the Department of Energy (DOE) G-1 aircraft, and/or the National Science Foundation/National Center for Atmospheric Research (NSF/NCAR) C-130 aircraft. Numerous flights also included segments designed to collect HSRL data over ground based AERONET network sites and during satellite overpasses of the Moderate Resolution Imaging Spectroradiome- ter (MODIS) and the Multiangle Imaging SpectroRadiometer (MISR) instruments. Coordinated flights with aircraft, ground based sensors, and satellite overpasses are summarized in Table 1. Figure 1 summarizes the B-200 flight tracks and indicates the location of the AERONET stations (Mexico City, Orizaba, Tamihua, T0, T1, T2, and Veracruz).

The NASA LaRC airborne HSRL system and algorithms are described in detail by Hair et al. (2008) and are briefly summarized here. The raw HSRL data are averaged over 100 shots $(0.5 \mathrm{~s}$ at $200 \mathrm{~Hz})$ temporally with $30 \mathrm{~m}$ vertical bins, which are analyzed to determine aerosol extinction, backscatter, and depolarization. The HSRL technique is employed for the $532 \mathrm{~nm}$ wavelength, utilizing the iodine vapor filter technique (Hair et al., 2001, 2008; Piironen et al., 1994). The received $532 \mathrm{~nm}$ backscatter return is split between three optical channels: (1) one measuring the backscatter (predominantly aerosol) polarized orthogonally to the transmitted polarization, (2) one measuring $10 \%$ of the molecular and aerosol backscatter polarized parallel to the transmitted polarization, and (3) one passing through an iodine vapor cell which absorbs the central portion of the backscatter spectrum, including all of the Mie backscatter, and transmits only the Doppler/pressure-broadened molecular backscatter. This third channel, (the "molecular channel") is used to retrieve the profile of extinction and all three channels are used to retrieve profiles of aerosol backscatter coefficient and aerosol depolarization. Equation (1) (corresponding to Eq. (6) in Hair et al., 2008) describes the determination of the $532 \mathrm{~nm}$ aerosol extinction coefficient $\left(\alpha_{\text {aer }}\right)$ from the measured power in molecular channel, $\left(P_{i 2}\right)$, range $(r)$, overlap function $(\Psi)$, filter function describing the molecular transmission through the iodine filter $(F)$, parallel molecular $\operatorname{backscatter}\left(\beta_{\mathrm{mol}}^{\|}\right)$, and molecular extinction $\left(\alpha_{\mathrm{mol}}\right)$ :

$\alpha_{\mathrm{aer}}=-\frac{1}{2} \frac{\partial}{\partial r} \ln \left(\frac{P_{i 2} \cdot r^{2}}{\Psi \cdot F \cdot \beta_{\mathrm{mol}}^{\|}}\right)-\alpha_{\mathrm{mol}}$

In this expression the molecular extinction and backscatter are calculated from modeled density profiles and the calculation is only performed where the overlap function is unity (approximately $2.5 \mathrm{~km}$ from the aircraft). Hair et al. (2008) describe the potential errors introduced in any of these quantities and found the $532 \mathrm{~nm}$ extinction systematic error to be less than $0.01 \mathrm{~km}^{-1}$ in typical aerosol loading. The aerosol extinction is calculated at $300 \mathrm{~m}$ vertical and $60 \mathrm{~s}$ temporal resolution (translating to $\sim 6 \mathrm{~km}$ horizontal resolution using nominal aircraft speed). The aerosol backscatter coefficient is derived from the measured attenuated total backscatter signal (molecular plus aerosol), the measured attenuated molecular backscatter signal, and molecular backscatter coefficient estimated from a model-derived air density profile. The aerosol backscatter coefficients are averaged over $10 \mathrm{~s}(\sim 1 \mathrm{~km}$ at nominal aircraft speed) in time and $30 \mathrm{~m}$ in altitude. The $532 \mathrm{~nm}$ extinction-to-backscatter ratio (hereafter referred to as "lidar ratio") is then calculated from the 
Table 1. $\times$ indicates comparison/validation/coordination: MODIS and MISR coincidences are indicated as over land (L) or water (W). AERONET coordinated stations are listed: TA = Tamihua, MC = Mexico City, $\mathrm{O}=$ Orizaba, and T0, T1, T2.

\begin{tabular}{|c|c|c|c|c|c|c|c|c|c|c|c|}
\hline \multirow{2}{*}{$\begin{array}{c}\text { Date } \\
(\mathrm{MM} / \mathrm{DD})\end{array}$} & \multirow{2}{*}{ Flight \# } & \multirow{2}{*}{$\begin{array}{l}\text { Begin time } \\
\text { (UTC) }\end{array}$} & \multirow{2}{*}{$\begin{array}{l}\text { End time } \\
\text { (UTC) }\end{array}$} & \multicolumn{7}{|c|}{ Coincident measurements } & \multirow{2}{*}{ Comments } \\
\hline & & & & G-1 & $\mathrm{C}-130$ & $\mathrm{~J}-31$ & AERONET & $\begin{array}{c}\text { MODIS } \\
\text { (Aqua) }\end{array}$ & $\begin{array}{c}\text { MODIS } \\
\text { (Terra) }\end{array}$ & MISR & \\
\hline \multirow[t]{2}{*}{ 03/01 } & 1 & $15: 38$ & 18:10 & & & & & & & & $\begin{array}{l}\text { Transit flights from NASA } \\
\text { LaRC to Houston }\end{array}$ \\
\hline & 2 & $19: 21$ & $21: 29$ & & & & & & & & \\
\hline $03 / 02$ & 1 & $15: 35$ & $17: 40$ & & & & & & & & $\begin{array}{l}\text { Transit from Houston to Ve- } \\
\text { racruz }\end{array}$ \\
\hline 03/06 & 1 & $15: 53$ & 18:41 & $x$ & & $x$ & T0, T1, MC & & $\mathrm{L}$ & $\mathrm{L}$ & \\
\hline $03 / 07$ & 1 & $16: 56$ & $20: 45$ & $x$ & & & T0, T1, MC, O & $\mathrm{L}$ & & & $\begin{array}{l}\text { Raster Pattern over Mexico } \\
\text { City }\end{array}$ \\
\hline $03 / 08$ & 1 & 18:54 & $21: 18$ & & & & & $\mathrm{~W}$ & & & Intended J-31 coordination \\
\hline 03/09 & 1 & $14: 45$ & 18:10 & $x$ & & & T0, T1, MC & & $\mathrm{L}$ & & $\begin{array}{l}\text { Raster pattern over Mexico } \\
\text { City to look at AM/PM out- } \\
\text { flow }\end{array}$ \\
\hline $03 / 13$ & 1 & $16: 18$ & 20:01 & & & & $\mathrm{T} 0, \mathrm{~T} 1, \mathrm{MC}$ & & $\mathrm{L}$ & $\mathrm{L}$ & $\begin{array}{l}\text { Flight intended to scout } \\
\text { aerosols for the G-1 }\end{array}$ \\
\hline $03 / 15$ & 1 & $15: 41$ & 19:05 & $x$ & & $x$ & $\mathrm{~T} 0, \mathrm{~T} 1, \mathrm{MC}$ & & $\mathrm{L}$ & $\mathrm{L}$ & \\
\hline $03 / 25$ & 1 & $21: 48$ & $23: 13$ & & & & & & & & $\begin{array}{l}\text { Transit back from Toluca to } \\
\text { Veracruz }\end{array}$ \\
\hline $03 / 26$ & 1 & $17: 00$ & $20: 25$ & & & & & & & & $\begin{array}{l}\text { Transmitter troubleshooting } \\
\text { on HSRL }\end{array}$ \\
\hline $03 / 27$ & 1 & $16: 45$ & $20: 25$ & $x$ & & & $\mathrm{~T} 0, \mathrm{~T} 1, \mathrm{~T} 2$ & & $\mathrm{~L}$ & & \\
\hline $03 / 28$ & 1 & $13: 57$ & $17: 43$ & & $x$ & & & & W & W & \\
\hline \multirow[t]{2}{*}{$03 / 29$} & 1 & $15: 49$ & $19: 36$ & & $x$ & & $\mathrm{~T} 0, \mathrm{~T} 1, \mathrm{O}$ & & $\mathrm{L}$ & $\mathrm{L}$ & \\
\hline & 2 & 21:04 & $00: 20$ & & $\times$ & & $\mathrm{T} 1, \mathrm{MC}, \mathrm{O}$ & & & & \\
\hline $03 / 31$ & 1 & $16: 19$ & 18:06 & & $x$ & & & & & & $\begin{array}{l}\text { Transit flights back to } \\
\text { NASA LaRC }\end{array}$ \\
\hline
\end{tabular}

ratio of the aerosol extinction and backscatter and is at the coarser resolution of the extinction product $(\sim 6 \mathrm{~km}$ horizontal, $300 \mathrm{~m}$ vertical resolution). The aerosol depolarization ratio, defined as the ratio between the aerosol backscatter polarized perpendicular and parallel to the transmitted laser beam, is computed from the measured total (molecular plus aerosol) depolarization ratio and the retrieved aerosol backscatter profile. This product is produced at the same resolution as the aerosol backscatter product $(\sim 1 \mathrm{~km}$ horizontal, $30 \mathrm{~m}$ vertical resolution).

At $1064 \mathrm{~nm}$, the standard backscatter lidar technique (Fernald, 1984) is employed to retrieve aerosol extinction and backscatter ( $\sim 1 \mathrm{~km}$ horizontal, $30 \mathrm{~m}$ vertical resolution) by assuming a lidar ratio between 30 and $40 \mathrm{sr}$, determined from a cluster retrieval similar to Cattrall et al. (2005). Prior to implementing this retrieval, the $1064 \mathrm{~nm}$ channel is calibrated to an estimate of total backscatter in that part of the profile that is both near the aircraft and exhibits a local minimum in the $532 \mathrm{~nm}$ aerosol backscatter profile. At the cali- bration altitude, the aerosol component of the total $1064 \mathrm{~nm}$ backscatter is estimated from the $532 \mathrm{~nm}$ aerosol backscatter determined via the HSRL technique by assuming the ratio of aerosol backscatter at $532 \mathrm{~nm}$ to that at $1064 \mathrm{~m}$ is 2.5 (Chudamani et al., 1996). The estimate of the molecular component of backscatter at the calibration altitude is calculated from the model-derived air density at the calibration altitude. The Fernald retrieval is then implemented to calculate the $1064 \mathrm{~nm}$ aerosol backscatter and extinction above and below the calibration altitude; however, unlike the $532 \mathrm{~nm}$ products, the $1064 \mathrm{~nm}$ aerosol backscatter and extinction are not independent as they both depend upon an assumed lidar ratio in the retrieval. Like the $532 \mathrm{~nm}$ channel, the $1064 \mathrm{~nm}$ channel also independently measures the backscatter polarized parallel and perpendicular to that of the transmitted beam. The $1064 \mathrm{~nm}$ aerosol depolarization ratio is calculated at the same resolution as the aerosol backscatter product $(\sim 1 \mathrm{~km}$ horizontal, $30 \mathrm{~m}$ vertical resolution). 


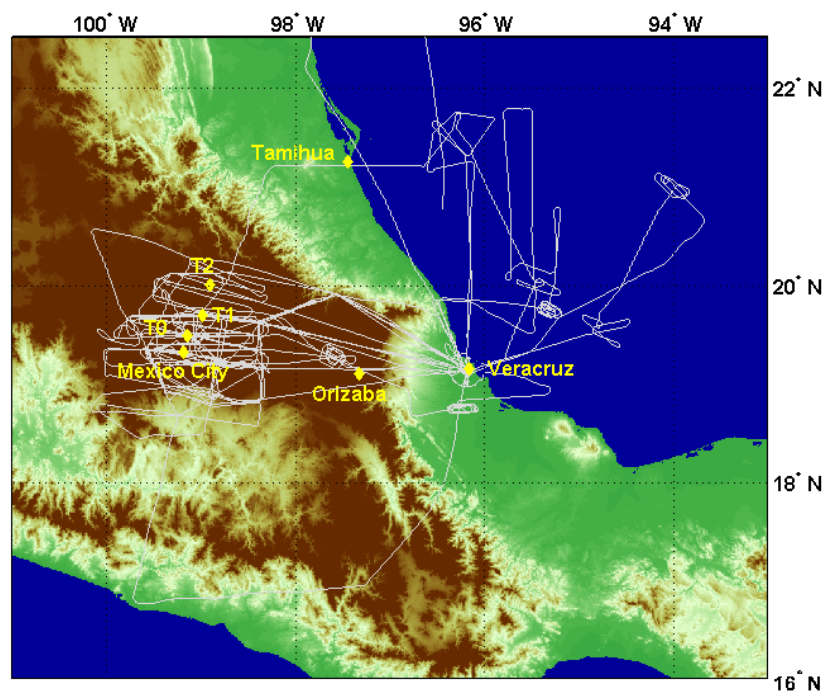

Fig. 1. Flight tracks of the NASA LaRC B-200 during MILAGRO (white). The yellow diamonds and labels indicate AERONET stations.

Random error estimates based on shot noise are provided for all HSRL products using a noise scale factor as detailed in Liu et al. (2006).

The data products available from the measurements can be analyzed in terms of extensive and intensive observables to gain insight on aerosol loading, aerosol radiative effects, and aerosol type. Extensive observables depend upon both aerosol loading and optical properties. Intensive observables are independent of aerosol loading and depend only on optical properties as determined by aerosol composition, size, and shape. The extensive profile products are aerosol backscatter at the two wavelengths and aerosol extinction at $532 \mathrm{~nm}$. The intensive profile products are the aerosol depolarization ratios at the two wavelengths, the ratio of aerosol backscatter at the two wavelengths, and the lidar ratio (i.e., the extinction-to-backscatter ratio) at $532 \mathrm{~nm}$. The aerosol depolarization ratio provides an indication of aerosol shape: spherical particles exhibit zero depolarization whereas irregularly shaped particles (e.g., dust) significantly depolarize the backscattered signal. Because the depolarization ratio is measured at both wavelengths, the wavelength dependence of the aerosol depolarization ratios can also be used to make additional inferences on aerosol morphology in the profile (e.g., the ratio of spherical-to-nonspherical backscatter (Sugimoto and Lee, 2006)). The wavelength dependence of the aerosol backscatter (WVD) is calculated in terms of the Angstrom exponent of the aerosol backscatter coefficient, $\beta_{a}$, and, while also influenced by aerosol composition, provides information on particle size: smaller particles generally exhibit a larger WVD than larger particles. The $532 \mathrm{~nm}$ lidar ratio is influenced by aerosol composition, morphology, and size and provides information useful in inferring aerosol type: e.g., the lidar ratio for more absorbing aerosols is generally larger than that for less absorbing aerosols. A more detailed description of the retrievals of the extensive and intensive data products is provided in Hair et al. (2008).

Column and layer products can be computed from the profile data, the most relevant of which for this paper is the aerosol optical depth. The $532 \mathrm{~nm}$ differential, or layer, aerosol optical depth is a profile of cumulative AOD (calculated from the two-way transmittance in the molecular channel) to each altitude bin, referenced to $2.5 \mathrm{~km}$ below the aircraft ( $300 \mathrm{~m}$ resolution). At $150 \mathrm{~m}$ above the ground a polynomial fit extends the differential AOD to the ground. The column-integrated AOD is the largest layer available in the differential AOD, extending from the ground up to $2.5 \mathrm{~km}$ below the aircraft.

Figure 2 shows examples of HSRL $532 \mathrm{~nm}$ aerosol backscatter and aerosol optical depth products from the second B-200 flight on 9 March 2006 (afternoon flight, 19.9523.00 UTC). This flight was an east-west raster pattern designed to look at the Mexico City basin region and the aerosol outflow to the north of the city and was coordinated with the G-1 aircraft. In these plots the column AOD and aerosol backscatter both show significant aerosol loading to the north of Mexico City. AODs observed in this flight were higher by $\sim 0.2$ than in the morning flight (not shown) in Mexico City and the region north of the city. A summary of the HSRL data products for one coordinated flight section, from 21.52 UTC to 21.85 UTC (note all times referenced in this paper are in fractional hour), denoted by the black arrow in Fig. 2a and the black arrow Fig. 2b, is presented in Fig. 3. Extensive observables are shown in Fig. 3a, b: $532 \mathrm{~nm}$ aerosol backscatter and extinction. Intensive observables are shown in Fig. 3c-f: the $532 \mathrm{~nm}$ aerosol depolarization ratio, the ratio of aerosol depolarization ratios $(1064 \mathrm{~nm} / 532 \mathrm{~nm})$ the $532 \mathrm{~nm}$ aerosol lidar ratio, and the aerosol backscatter wavelength dependence. The thin white lines in these plots are the digital elevation map (DEM) ground altitude above mean sea level. The thick white line in Fig. 3a is the G-1 flight track, which will be discussed below.

Figure 3 demonstrates the measurements that HSRL can make of a highly variable aerosol mass in a relatively short time, yet over a large spatial region with fine vertical resolution: approximately $120 \mathrm{~km}$ over $20 \mathrm{~min}$ along this particular leg. The variability of aerosol intensive properties displayed indicate variations in aerosol optical and physical characteristics and signify that there are at least two separate aerosol types observed in this scene. The observed aerosol lidar ratios between 21.625 and 21.75 UTC are high (40-50 sr) from the ground up to $6 \mathrm{~km}$, which coupled with aerosol $532 \mathrm{~nm}$ depolarization ratios around $\sim 0.1$ and higher aerosol wavelength dependence in the same region $(\mathrm{WVD}<0.5)$ indicates that the aerosols in this region were likely dominated by an urban aerosol air mass but contained a significant amount of dust particles. To the east of this region, from 21.75 UTC to 21.9 UTC, the lidar ratios are around $30-40 \mathrm{sr}$, with WVD 


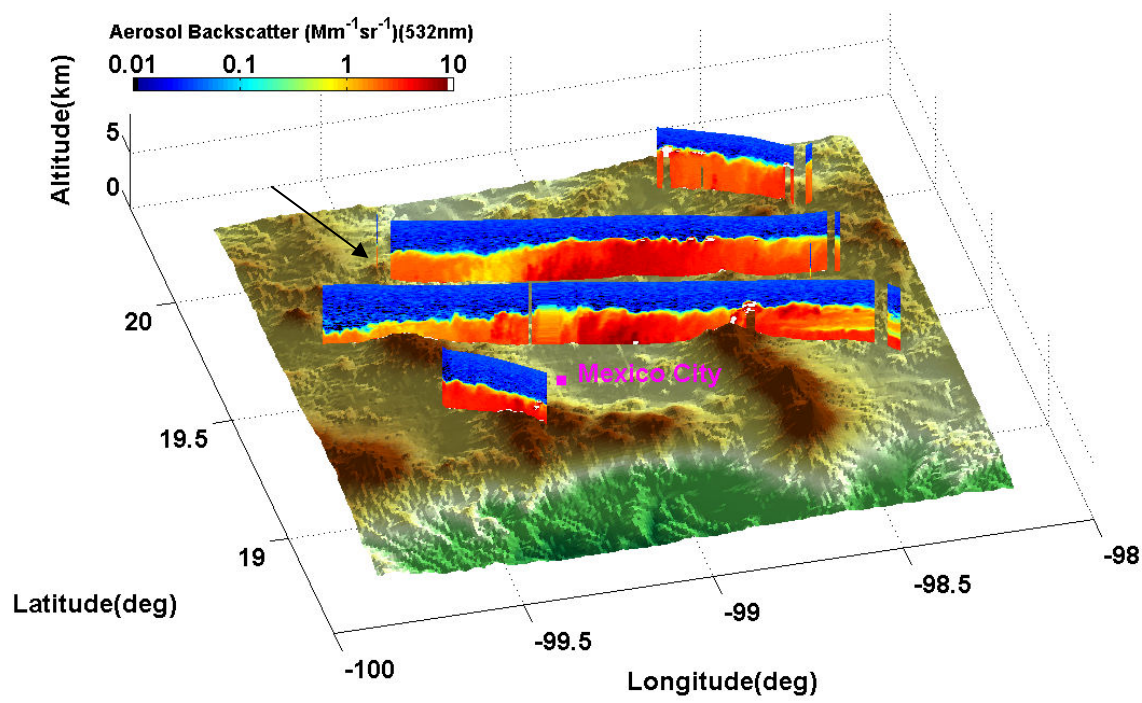

(a)

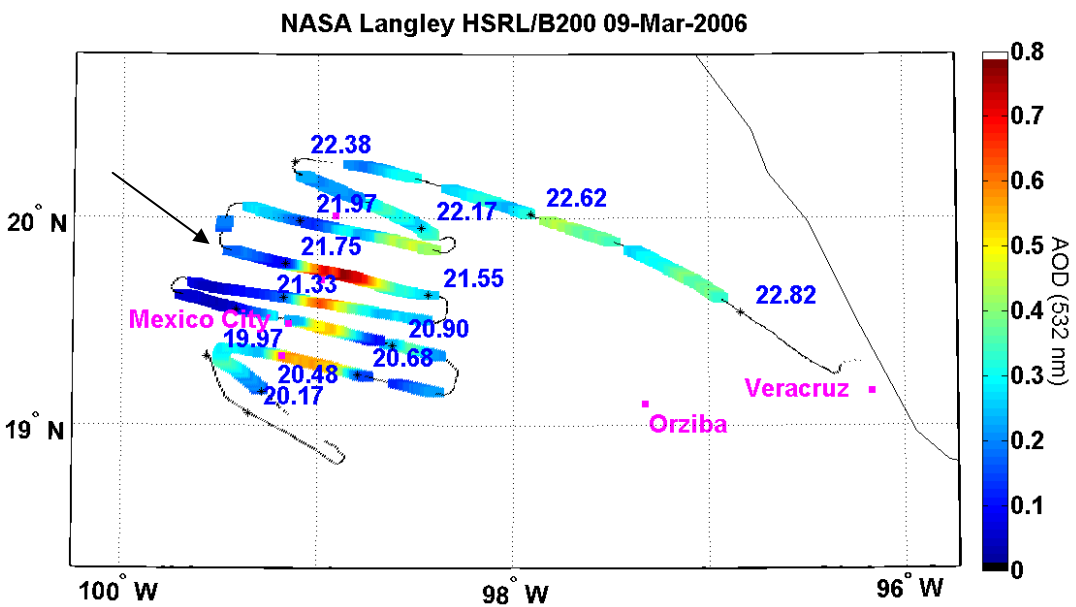

(b)

Fig. 2. Flight track maps of $532 \mathrm{~nm}$ aerosol backscatter coefficient (only every other leg is plotted for clarity) (a) and $532 \mathrm{~nm}$ aerosol optical depth (b) on 9 March 2006 over the Mexico City basin. The black arrow in each (a) and (b) indicates the leg that is coordinated with the G-1. Mexico City is marked with a magenta square in both (a) and (b), and the times shown in (b) are in fractional hour (UTC).

$\sim 0$ and depolarization $\sim 0.2$, indicative of dust dominated aerosol mass. It should be noted that the aerosol depolarization was elevated $(\delta>0.05)$ for many of the MILAGRO measurements, indicating a nonspherical (dust) component in most of the measurements.

The DOE G-1 flew a stacked pattern coordinated for close temporal coincidence with the B200 along this flight leg, thereby providing in situ aerosol and trace gas measurements along three level leg altitudes in the lidar curtain. The G1 started along this leg at $21.8 \mathrm{UTC}(\sim 5 \mathrm{~km})$ on the eastern portion of the area depicted in Fig. 3 and transected the region where HSRL measured high backscatter three times before ending the coincident pattern at $22.6 \mathrm{UTC}(\sim 3 \mathrm{~km})$, indicated by the thick white line in Fig. 3a.
Figure 4 contains time-height curtain plots showing a subset of the parameters measured by the in-situ sensors onboard the G-1. The color coded lines representing the G-1 measurements are thickened for plotting purposes and hence appear to extend $500 \mathrm{~m}$ vertically whereas the actual sampling altitude of the G-1 was constant to within $50 \mathrm{~m}$ along any given level altitude segment. The G-1 instruments measured total aerosol scattering with a three wavelength TSI model 3563 nephelometer $(450,550$, and $700 \mathrm{~nm})$ and aerosol absorption with a Particle Soot Absorbance Photometer (PSAP) at three wavelengths $(461.1,522.7$, and $648.3 \mathrm{~nm})$. The G-1 aerosol scattering is plotted in Fig. 4a, and the extinction and absorption were used in conjunction (Fig. 4b, c) to produce aerosol extinction and single scattering albedo (SSA) at 

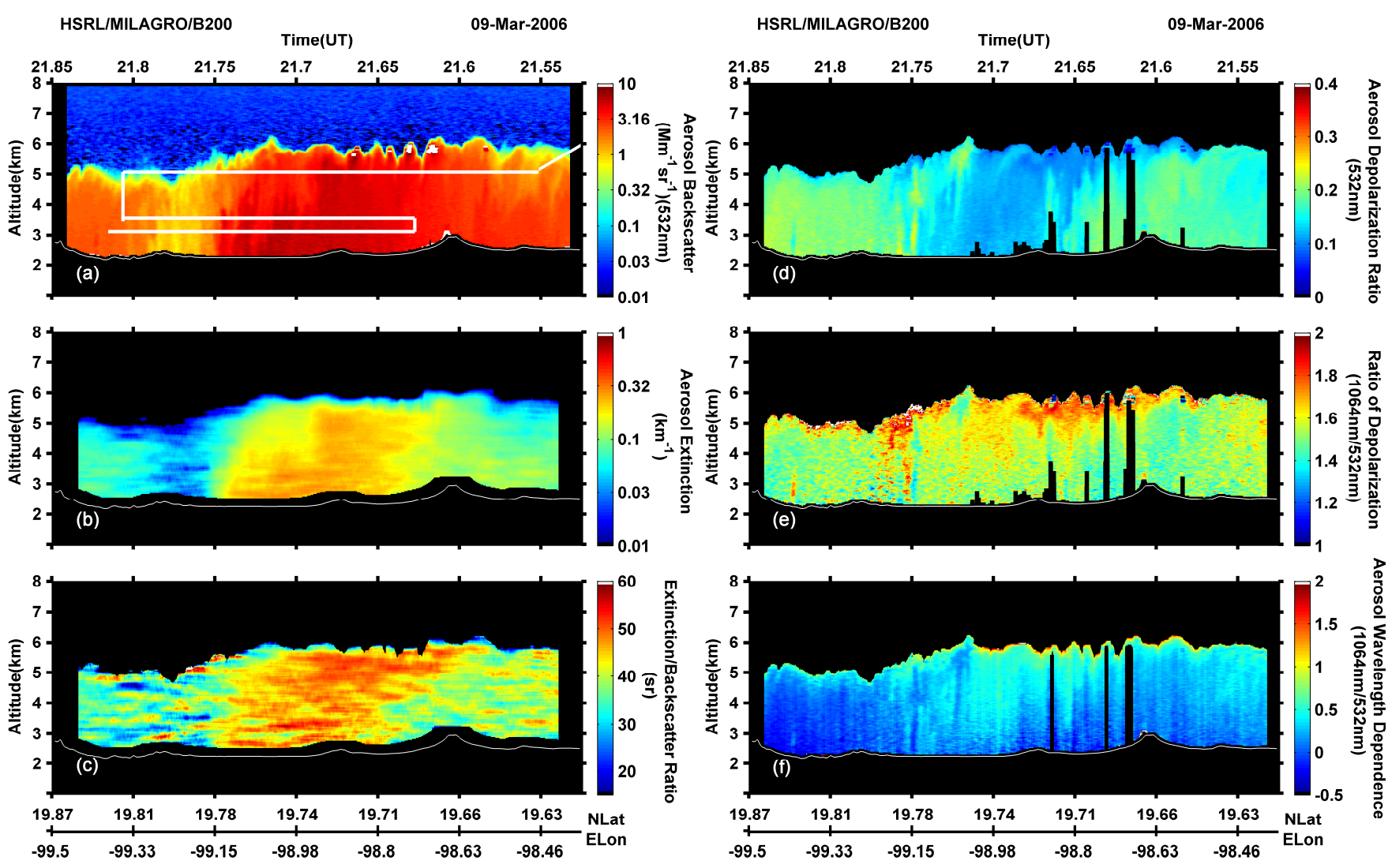

Fig. 3. Time height plots of $532 \mathrm{~nm}$ aerosol backscatter (a), $532 \mathrm{~nm}$ aerosol extinction (b), $532 \mathrm{~nm}$ lidar ratio (c), aerosol depolarization ratio at $532 \mathrm{~nm}(\mathbf{d})$, ratio of the $1064 \mathrm{~nm}$ depolarization ratio to the $532 \mathrm{~nm}$ depolarization ratio (e), and the aerosol backscatter wavelength dependence (f). The thick white line in aerosol backscatter indicates the altitude that the G-1 aircraft flew making in situ measurements along this flight track. Note that the top axis is the HSRL time and only the G-1 longitude is represented here; the G-1 flew this flight track within an hour of the HSRL times (21.8 UTC to 22.6 UTC).

$532 \mathrm{~nm}$ (scattering and absorption were scaled with wavelength and an Angstrom coefficient of unity). A Passive Cavity Aerosol Spectrometer (PCASP) X100 with SPP 200 electronics measured the total number density of aerosols (30 bins, 0.1 to $3 \mu \mathrm{m}$ ) shown in Fig. $4 \mathrm{~d}$ and the ozone concentration was measured by a UV-Absorbance Ozone Analyzer, TEI Model 49-100 (Fig. 4e), while relative humidity (Fig. 4f), is calculated from the ambient and dew point temperatures measured with a Rosemount 102E temperature probe and a General Eastern 1011B hygrometer. A quantitative discussion of the G-1 extinctions is provided in Sect. 3.3.

Inside of the region located in between $-98.6 \mathrm{E}$ and $-99.0 \mathrm{E}$ longitude there are elevated aerosol counts in the PCASP, especially at higher altitudes, as well as elevated scattering, extinction, ozone, and relative humidity. The SSA is $\sim 0.88$ in the lower altitude legs in the region of high aerosol extinction and $\sim 0.95$ in the higher altitude leg in the same region. Taken together, these measurements also indicate an aerosol source largely of urban origin, agreeing with the inference on the dominant aerosol mass made via the HSRL observations. Figures 3 and 4 illustrate the complementary nature of the HSRL remotely sensed and airborne in situ observations. The high spatial and temporal resolution HSRL curtains add context for interpretation of the G-1 data and enable extrapolation of the inferences made from the G1 measurements to other altitudes and locations. (Another example of the use of the HSRL to provide spatial and temporal context to in-situ measurements on the C-130 aircraft is presented in Sect. 3.1.) On the other hand, the detailed aerosol composition, size, morphology, and optical property measurements from the in-situ instruments on the G-1 (and other platforms) are useful for assessing the inferences of aerosol type made from the HSRL data. This assessment of HSRL typing skill enables identification of aerosol type to be made with higher confidence for the entire HSRL data set, including vast regions where there are no accompanying in situ observations. 

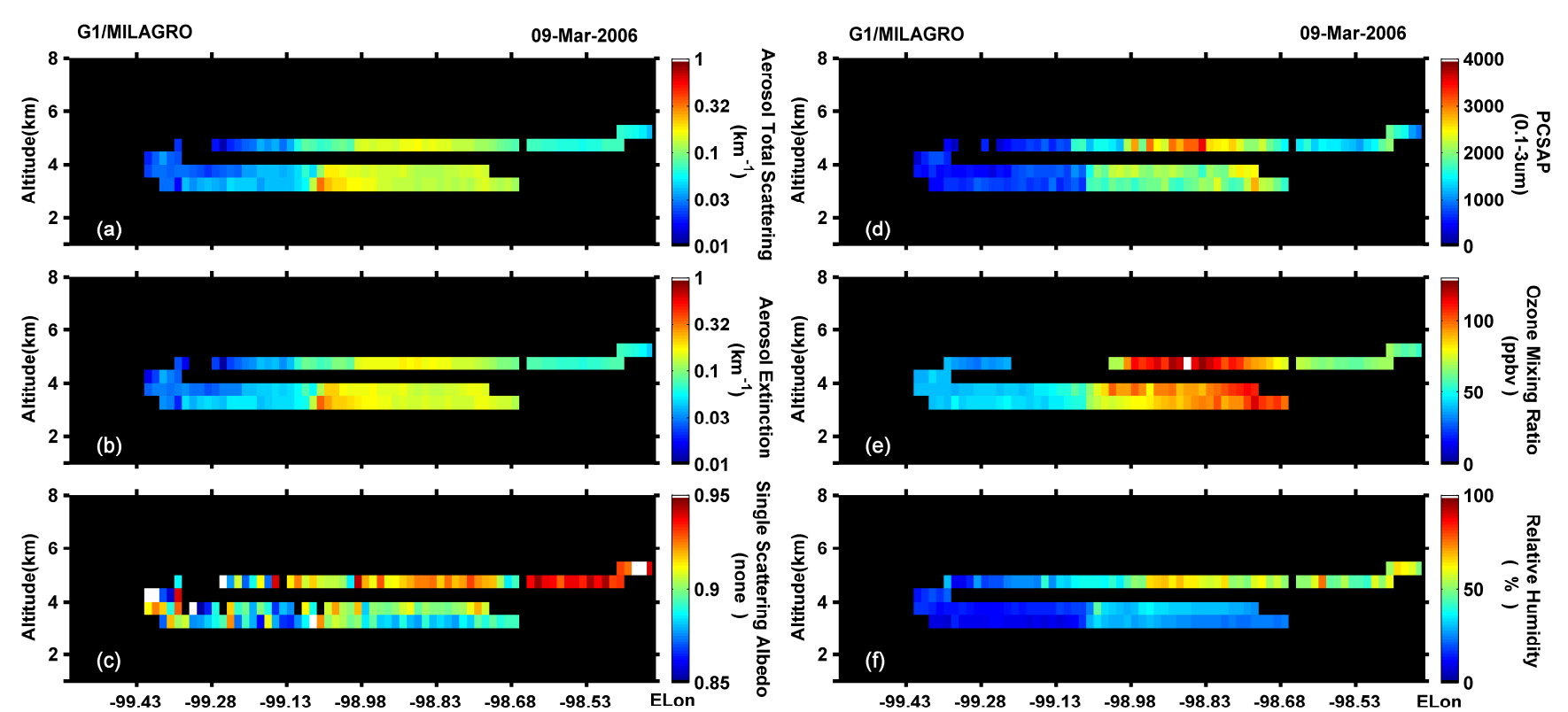

Fig. 4. A subset of measurements from the G-1 aircraft including aerosol total scattering (a), $532 \mathrm{~nm}$ aerosol extinction (b), $532 \mathrm{~nm}$ single scattering albedo (c), aerosol number density $(0.1-3 \mu \mathrm{m})(\mathbf{d})$, ozone mixing ratio (e), and relative humidity (f).

\section{HSRL extinction and AOD comparisons}

The coordinated measurement efforts in MILAGRO provided the opportunity to assess the HSRL aerosol extinction and optical thickness profiles via comparison with profiles derived from two other airborne instruments employing different measurement techniques: (1) the 14-channel NASA Ames Airborne Tracking Sunphotometer AATS-14 on the J-31 aircraft (Russell et al., 2007; Livingston et al., 2009) and (2) the in situ nephelometer measurements of aerosol scattering and PSAP measurements of aerosol absorption from the Hawaii Group for Environmental Aerosol Research (HiGEAR) on the NSF/NCAR C-130 aircraft (McNaughton et al., 2009). Comparisons of temporally and spatially coincident aerosol extinction measurements derived from the nephelometer and PSAP instruments are also shown to validate the HSRL extinction. Aerosol optical depths derived from the HSRL measurements are also compared with the 14-channel NASA AATS-14 and the AERONET groundbased sun photometer AOD measurements.

The linear regressions presented here were preformed using the linear least squares bisector technique (Sprent and Dolby, 1980). This follows the example of Schmid et al. (2006) and accounts for the fact that neither dataset is the "truth" and should therefore be treated as the independent variable. Similarly, the bias and rms differences reported here were calculated following Schmid et al. (2006).

All of the vertical profiles and related scatterplots presented here have interpolated the profiles to a common $50 \mathrm{~m}$ vertical grid, determined from the AATS-14 retrieval. This altitude grid is slightly oversampled for the HSRL and
AATS-14 extinction measurements, and in addition to the potential for vertical lofting of air masses, we cannot consider adjacent points unique. This should have little effect on the bias and regression parameters reported here, however care should be taken in interpreting the profile data shown here.

\subsection{HiGEAR}

The HiGEAR aerosol scattering measurements are measured with a TSI 3563 three-wavelength $(450,550,700 \mathrm{~nm})$ nephelometer and the HiGEAR aerosol absorption measurements were determined from a three-wavelength $(470,530$, $660 \mathrm{~nm}$ ) Radiance Research particle soot absorption photometer. The aerosol scattering was scaled to $530 \mathrm{~nm}$ based on the wavelength dependence of the scattering measured at $450 \mathrm{~nm}$ and $550 \mathrm{~nm}$. The aerosol sample was dried through ram heating and cabin temperature higher than ambient, with the dry aerosol scattering measured by the nephelometer is corrected to ambient relative humidity using the approximation (Kasten, 1969) given by Eq. (3):

$\sigma_{s}=\sigma_{s, d}\left(\frac{1-\mathrm{RH}}{1-\mathrm{RH}_{d}}\right)^{-\gamma}$

where $\sigma_{s}$ is the light scattering coefficient at relative humidity RH (value between 0 and 1) and $\sigma_{s, d}$ is the light scattering coefficient at dry relative humidity, $\mathrm{RH}_{d}$. For this analysis the empirical fitting parameter, $\gamma$, was determined from an average value of the $f(R H)$ curves obtained with a humidified nephelometer suite on the DC-8 for MILAGRO. McNaughton et al. (2009) found the $f(\mathrm{RH})$ curves measured in the flight configuration to be well calibrated with theoretical 
curves for both ammoniam sulfate and sea salt within $25 \%$. On average for MILAGRO the parameter $\gamma$ from this instrumentation was found to be 0.49 above $2 \mathrm{~km}$ and 0.61 below $2 \mathrm{~km}$. Additionally, the HiGEAR absorption was corrected for the interference of scattering and bias in manufacturer's calibration (Virkkula et al., 2005). Aerosol extinction is then the sum of the scattering and absorption at $530 \mathrm{~nm}$ and scaled to $532 \mathrm{~nm}$ with an assumed Angstrom coefficient of unity.

Closely coordinated maneuvers between the B-200 and C130 were conducted on three dates. These maneuvers consisted of the B-200 with the HSRL flying "racetrack" patterns over ascending/descending spirals of the C-130 with the HiGEAR instrumentation and yielded a total of four HiGEAR vertical profiles useful for intercomparison with the HSRL data. Because the HiGEAR extinction profiles were acquired at a higher resolution than HSRL the HiGEAR extinction profiles were smoothed with a $300 \mathrm{~m}$ moving average to be consistent with the filter applied to the HSRL extinction profile.

These comparison profiles are all coincident in time to within $5 \mathrm{~min}$, making insignificant any differences due to temporal variation. However horizontal aerosol gradients do lead to differences in the HSRL and HiGEAR extinction profiles simply due to differences in horizontal sampling, i.e., the HiGEAR data being acquired through ascending/descending spirals of the C-130 and the HSRL data being acquired in a B-200 "race-track" pattern over the C-130 spirals. Figure 5a shows an example of this effect with a coincident spiral of the C-130 and corresponding track of the B-200 on 29 March 2006. The $532 \mathrm{~nm}$ column AOD measured by HSRL is also plotted on the HSRL track and clearly illustrates that the AOD on the southern leg is higher than the northern leg by $\sim 0.1$. The aerosol scattering ratio (the ratio of aerosol backscatter to molecular backscatter) curtain plot shows this north-south difference as well, as large changes in the scattering within the southern leg between $1 \mathrm{~km}$ and $2 \mathrm{~km}$. The effect can also be seen in the line plot comparison of extinction, where the HSRL profiles are shown for an average of just the northern flight legs and again over all flight legs in Fig. 5c. The largest differences in extinction are seen between $1.4 \mathrm{~km}$ and $2.0 \mathrm{~km}$ where the $\mathrm{C}-130$ was on the northern half of its spiral from $1.4 \mathrm{~km}$ to $1.8 \mathrm{~km}$, thereby missing the thick aerosol mass $11 \mathrm{~km}$ to the south seen in the HSRL data. Using only the northern legs yields some discrepancies near $1100 \mathrm{~m}$ as the $\mathrm{C}-130$ was at the southern track at that altitude. All other coincident spirals were investigated for sharp spatial gradients that could lead to potentially different air masses reported in the subsequent comparisons. Deviations in HSRL AOD were generally less than 0.025 over the spiral region in all other cases.

Coincident aerosol extinction profiles from HSRL and HiGEAR are plotted in Fig. 6. Overall, the comparisons show the HSRL profiles of aerosol extinction to be generally in excellent agreement with the extinction profiles derived from HiGEAR. On 10 March 2006 the relative humidity was below $50 \%$, leading to small humidification factor corrections, which is also where the agreement is best (Fig. 6a). However on 28 March and 29 March 2006 (Fig. 6b, c, and d) the relative humidity was greater than $75 \%$ in the boundary layer and there are more disparities in the HSRL and HiGEAR aerosol extinction comparisons, potentially due to errors introduced in the humidification correction, which corresponds to a $30 \%$ to $45 \%$ enhancement of aerosol scattering for a relative humidity of $60 \%$.

All coincident HSRL and HiGEAR extinction measurements are summarized in Fig. 7. The HSRL and HiGEAR extinctions are in good agreement over a wide range of aerosol extinctions, from $\sim 0 \mathrm{~km}^{-1}$ to $0.2 \mathrm{~km}^{-1}$, with a bias difference of $-0.0011 \mathrm{~km}^{-1}(-2.6 \%)$ (HSRL lower) and good correlation. Results from the regression are shown in Table 2. As observed above, the HiGEAR data are measured in a dry environment and corrected for relative humidity. In order to minimize the impact of relative humidity the regression was performed on only the data measured below $65 \%$ relative humidity, which were found to have a bias of $-0.0044 \mathrm{~km}^{-1}$ $(-1.5 \%)$ (HSRL lower). The regression results for the low $(<65 \%)$ RH points only are summarized in Table 3 . Inclusion of relative humidity between $65 \%$ and $100 \%$ in the regression yields a bias difference ranging from $-0.0011 \mathrm{~km}^{-1}$ to $0.0006 \mathrm{~km}^{-1}$ (-2.6\% to $\left.1.6 \%\right)$ with good correlation and similar slopes remaining consistent throughout the range of relative humidity included. The changes observed by limiting the relative humidity are small and leads us to conclude that the bias is nearly zero in this case and the HiGEAR humidity correction is adequate.

\subsection{AATS-14}

The HSRL and AATS-14 instruments sampled the same region on a total of five coincident flights; however, cloud interference reduced the number of useful comparisons to three cases corresponding to three J-31 vertical profiles. The AATS AODs obtained during these profiles were scaled with wavelength to $532 \mathrm{~nm}$ using an Angstrom coefficient derived from the AATS $519 \mathrm{~nm}$ and $604 \mathrm{~nm}$ AODs. A corresponding aerosol extinction profile was calculated from each AATS 532-nm AOD profile using a multi-step procedure based on that described in Schmid et al. (2003). This approach consists of binning the AODs with altitude, fitting the binned AOD values with a smoothing spline function, and then numerically differentiating the spline fit. For the MILAGRO AATS measurements, each reported extinction profile represents the mean of a series of retrieval runs in which the vertical bin width was varied from $20 \mathrm{~m}$ to $300 \mathrm{~m}$ in increments of $20 \mathrm{~m}$, and the spline smoothing parameter was varied over a range of values chosen to minimize, without oversmoothing the AOD profile, the effects of spatial and temporal AOD inhomogeneities that can result in measurements of increasing AOD with altitude. The final extinction profile is reported at a vertical spacing of $50 \mathrm{~m}$, where each retrieval 

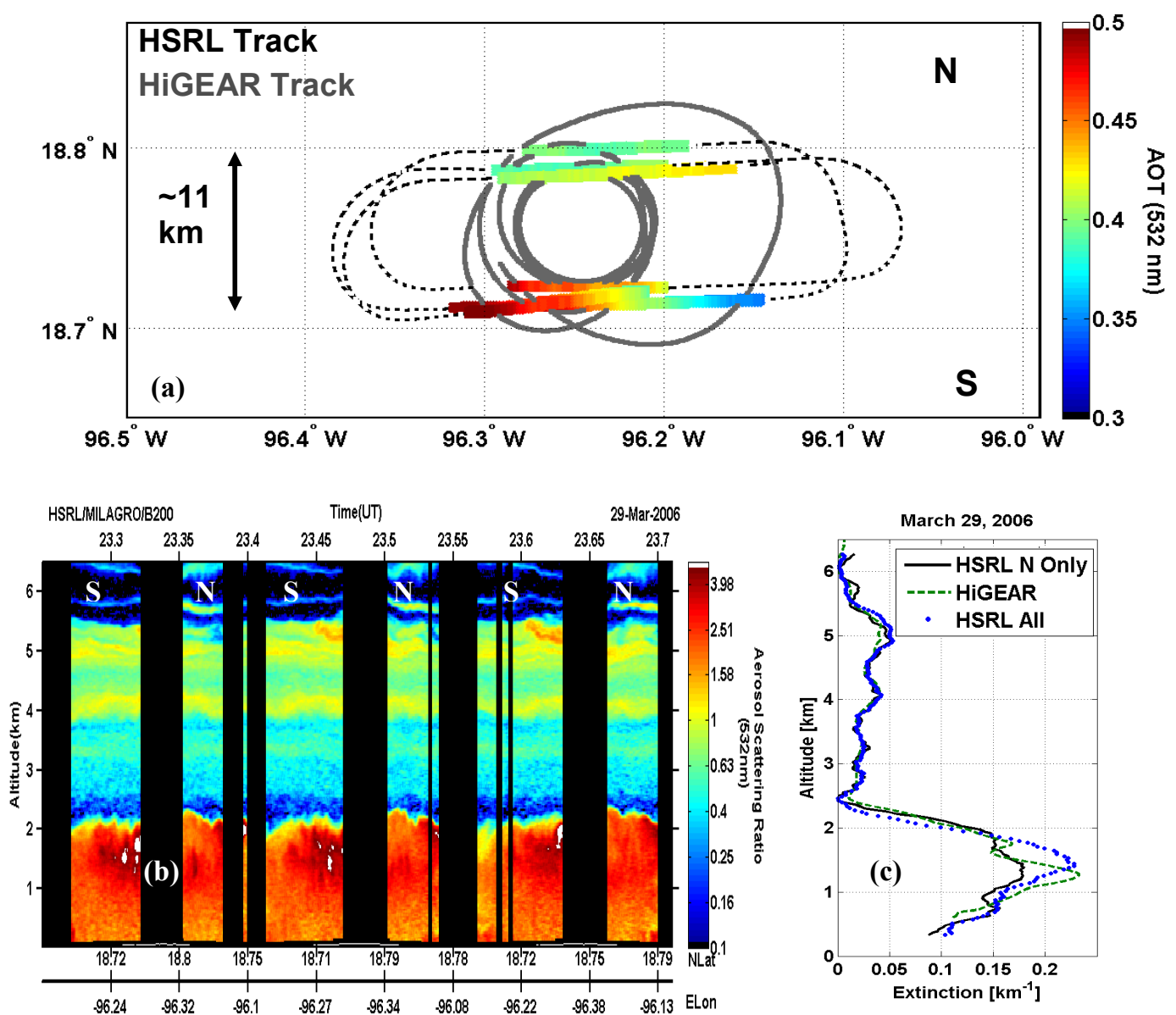

Fig. 5. 29 March 2006 coincident HSRL (black dashed) and HiGEAR (grey) flight tracks with HSRL 523 nm AOD shown along the straight legs (a), $532 \mathrm{~nm}$ backscatter ratio time-height plot over the same time period with the north and south legs indicated (b), average extinction profile from HiGEAR (green, dashed) and HSRL, with HSRL data averaged over the northern legs only (black, solid) and also over both the northern and southern legs (blue, dotted) (c).

Table 2. Summary of all extinction and AOD comparisons presented in Sect. 3.

\begin{tabular}{|c|c|c|c|c|c|c|c|c|c|}
\hline & $\begin{array}{l}\text { Wavelength } \\
\quad(\mathrm{nm})\end{array}$ & $\begin{array}{c}\text { Number of } \\
\text { points }\end{array}$ & Bias difference & $\begin{array}{l}\text { Bias percent } \\
\text { difference }\end{array}$ & rms difference & $\begin{array}{l}\text { rms percent } \\
\text { difference }\end{array}$ & Slope & Intercept & $R^{2}$ \\
\hline HiGEAR & 532 & 624 & $-0.0011 \mathrm{~km}^{-1}$ & $-2.6 \%$ & $0.011 \mathrm{~km}^{-1}$ & $22.6 \%$ & 1.09 & -0.0029 & 0.94 \\
\hline AATS-14 Extinction & 532 & 219 & $-0.00029 \mathrm{~km}^{-1}$ & $-0.96 \%$ & $0.013 \mathrm{~km}^{-1}$ & $43.4 \%$ & 0.96 & -0.0015 & 0.73 \\
\hline AATS-14 AOD & 532 & 223 & -0.0032 & $-6.5 \%$ & 0.0079 & $15.6 \%$ & 1.01 & 0.0028 & 0.98 \\
\hline G-1 Neph+PSAP & 532 & 3642 & $-0.00032 \mathrm{~km}^{-1}$ & $-0.27 \%$ & $0.036 \mathrm{~km}^{-1}$ & $30.6 \%$ & 1.13 & -0.015 & 0.92 \\
\hline AERONET & 532 & 10 & -0.0045 & $-1.8 \%$ & 0.056 & $22.1 \%$ & 0.96 & 0.016 & 0.64 \\
\hline
\end{tabular}

was interpolated to the pre-defined 50-m vertical grid before calculating the mean. The HSRL data were binned to the same $50 \mathrm{~m}$ vertical grid to which AATS-14 extinction profiles are reported. Figure 8 shows the resulting extinction and raw (not binned) differential AOD profiles for $532 \mathrm{~nm}$, all showing excellent agreement. The differential AOD values are normalized such that the value reported at any altitude bin presented here represents the optical depth of the aerosols located between that altitude and the maximum altitude attained by the $\mathrm{J}-31$ in each spiral $(\sim 4.8 \mathrm{~km})$. Normalizing the differential AOD to zero the maximum altitude of the $\mathrm{J}$ 31 was done to eliminate potential AOD offsets between the HSRL and the AATS-14 AOD measurements due to aerosols above the altitude of the B-200 which would not be observed by the nadir-viewing HSRL instrument. 
Table 3. Summary of dry $(\mathrm{RH}<65 \%)$ extinction comparisons for presented in Sect. 3 for measurements with a relative humidity correction.

\begin{tabular}{|c|c|c|c|c|c|c|c|c|c|}
\hline & $\begin{array}{l}\text { Wavelength } \\
\quad(\mathrm{nm})\end{array}$ & $\begin{array}{l}\text { Number of } \\
\text { points }\end{array}$ & Bias difference & $\begin{array}{c}\text { Bias percent } \\
\text { difference }\end{array}$ & rms difference & $\begin{array}{l}\text { rms percent } \\
\text { difference }\end{array}$ & Slope & Intercept & $R^{2}$ \\
\hline HiGEAR & 532 & 472 & $-0.0044 \mathrm{~km}^{-1}$ & $-1.5 \%$ & $0.0080 \mathrm{~km}^{-1}$ & $26.8 \%$ & 1.05 & -0.0011 & 0.88 \\
\hline G-1 Neph+PSAP & 532 & 3465 & $0.0031 \mathrm{~km}^{-1}$ & $2.9 \%$ & $0.029 \mathrm{~km}^{-1}$ & $27.7 \%$ & 1.07 & -0.011 & 0.93 \\
\hline
\end{tabular}
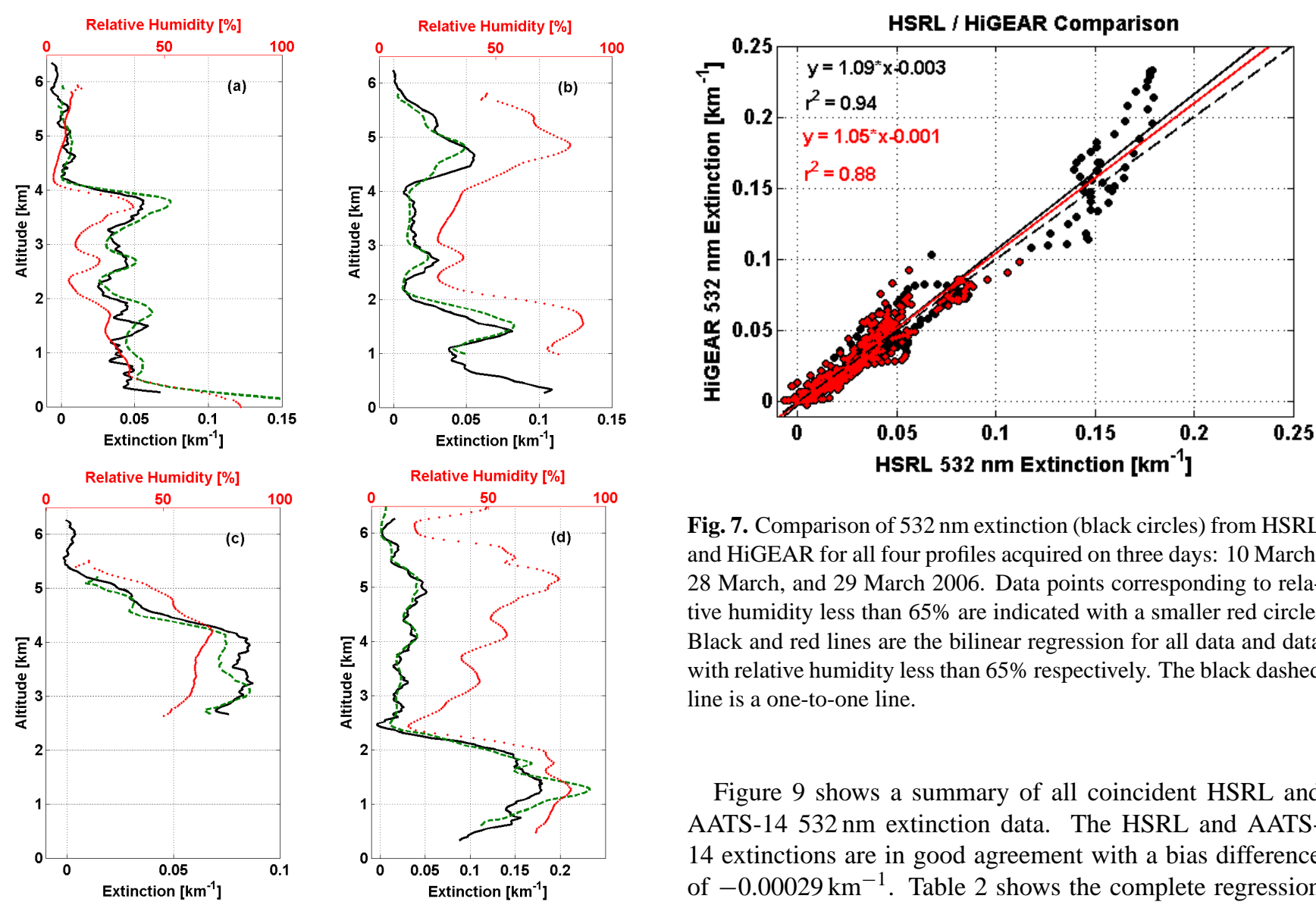

Fig. 7. Comparison of $532 \mathrm{~nm}$ extinction (black circles) from HSRL and HiGEAR for all four profiles acquired on three days: 10 March, 28 March, and 29 March 2006. Data points corresponding to relative humidity less than $65 \%$ are indicated with a smaller red circle. Black and red lines are the bilinear regression for all data and data with relative humidity less than $65 \%$ respectively. The black dashed line is a one-to-one line.

Figure 9 shows a summary of all coincident HSRL and AATS-14 $532 \mathrm{~nm}$ extinction data. The HSRL and AATS14 extinctions are in good agreement with a bias difference of $-0.00029 \mathrm{~km}^{-1}$. Table 2 shows the complete regression statistics. Note that, compared to HiGEAR, the range of extinction is smaller by almost a factor of two. Consequently, the inherent uncertainty in both HSRL and AATS-14 extinction measurements is larger in a relative sense for this smaller range. The lower correlation compared to HiGEAR may be due to several factors. First, it is possible that HSRL and AATS-14 can potentially measure slightly different air masses (down looking lidar vs. sun photometer-to-sun path). These spirals all had the solar zenith angle smaller than 40 degrees which could lead to a maximum horizontal sampling offset of $7 \mathrm{~km}$ (HSRL sampling at $8.5 \mathrm{~km}$ and AATS14 viewing the volume from near the surface). Similar to the HiGEAR comparisons, these measurements can be affected by horizontal gradients. Horizontal gradients were probably present in the 12 March 2006 case, for which the AATS-14 AOD nonphysically increases with altitude, probably due to an artifact of the sampling geometry (i.e., moving 

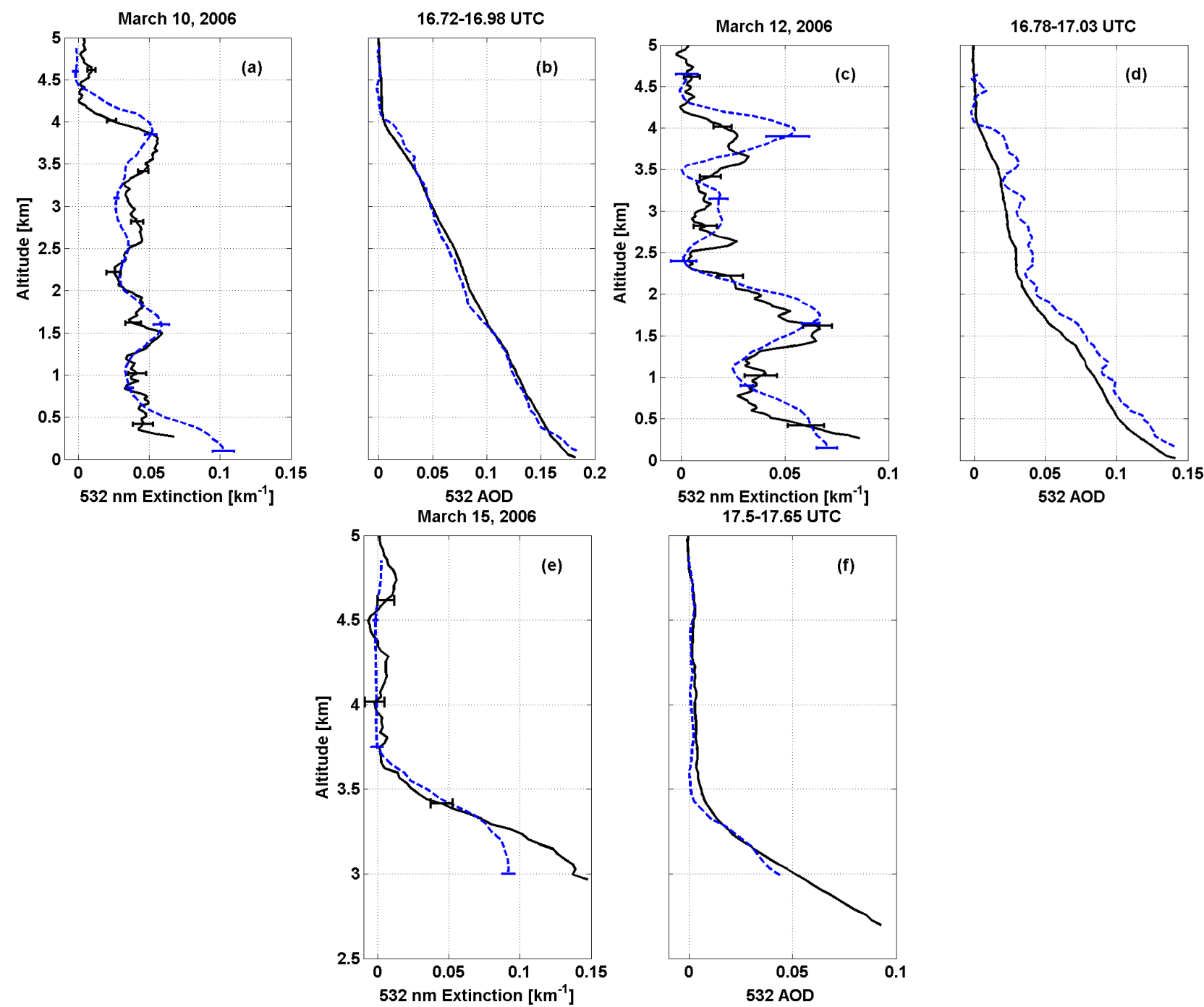

Fig. 8. Profile comparisons of HSRL (black, solid) and AATS-14 (blue, dashed) aerosol extinction at 532 nm (a, c, e) and differential AOD at $532 \mathrm{~nm}(\mathbf{b}, \mathbf{d}, \mathbf{f})$. These are from three spirals on 10 March 2006 (a, b), 12 March (c, d) and 15 March 2006 (e, f). On 15 March 2006 the lower limit is $2.5 \mathrm{~km}$ because this spiral was over vertically varying terrain with surface altitudes up to $2.6 \mathrm{~km}$. Note that the HSRL $532 \mathrm{~nm}$ AOD profiles extend closer to the ground than the HSRL extinction because of the extrapolation. Random uncertainty for HSRL $532 \mathrm{~nm}$ extinction is plotted; corresponding AATS extinction uncertainties are described in the text.

into a region of higher aerosol loading on one side of the spiral). It is difficult to assess any horizontal gradient from the HSRL observations for this case. The J-31 spiral was overflown by the B-200 in only one direction, with very little gradient $(\triangle \mathrm{AOD}<0.01)$ observed. This geometry would be sensitive to a gradient in aerosol loading on a different bearing from the J-31 spiral, and, in general, the nadir-only HSRL data cannot provide information on horizontal gradients in aerosol or cirrus above the B-200 along the path from the AATS-14 to the sun. Some of the outlying points in Fig. 9 are possibly due to cloud contamination above the AATS-14. One example of this was on 15 March 2006 (Fig. 8e, f) where the AATS-14 AOD data indicate there was significant cloud screening and only a few points went into the extinction calculation near the surface, causing differences up to $50 \%$.

The error bars in Figs. 8 and 9 are the random uncertainty estimates in the HSRL product. The error bars on the AATS extinction values for a particular profile were derived by combining, in an rms sense, the standard deviation of the set of retrieval results with an estimate of the uncertainty (Eq. 5 in Redemann et al., 2003) due to spatial and/or temporal inhomogeneity of the aerosol field during the vertical profile. These uncertainties were used to weight the bilinear regression, which yielded a similar slope $(1.05 \pm 0.04)$ 


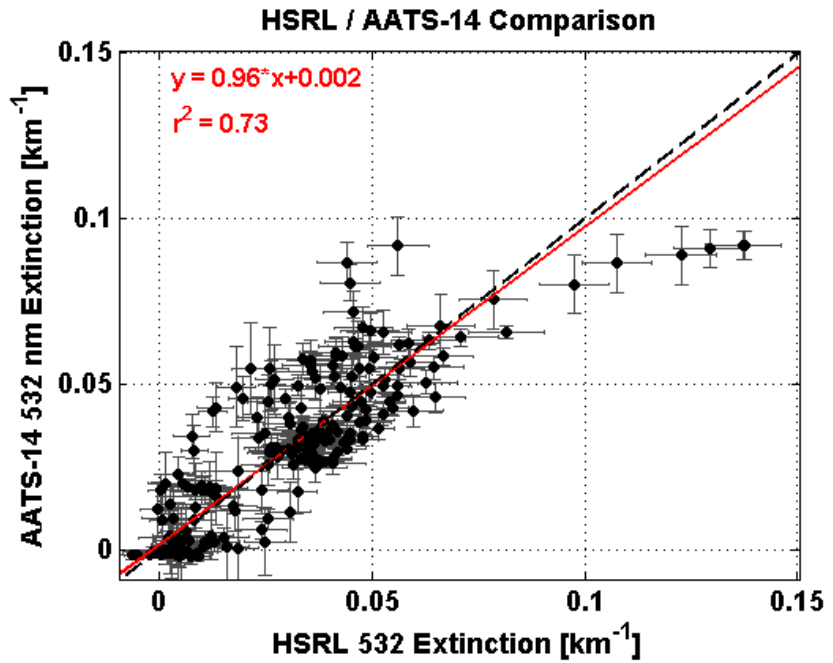

Fig. 9. Comparison of $532 \mathrm{~nm}$ extinction from HSRL and AATS-14 for all three profiles acquired on 10 March, 12 March, and 15 March 2006. Red and black (dashed) lines indicate the bilinear regression and the one to one line, respectively.

and intercept $(-0.001 \pm 0.001)$ as the unweighted regression. Uncertainty estimates were not available for in-situ measurements so no other weighted regressions were performed.

As mentioned above the differential AOD is a more fundamental measurement for both HSRL and AATS-14 which is presented in Fig. 10. For this dataset the bias difference is $-0.0032(-6.5 \%)$ (HSRL lower). The complete regression statistics are tabulated in Table 2. The good agreement of the differential AOD supports the observation that some of the spread observed in the extinction comparison is likely due to differences in methods for calculating aerosol extinction and differences in vertical smoothing and/or resolution related to doing so.

\subsection{G-1 extinction measurements (nephelometer + PSAP)}

The G-1 did not perform any spirals coincident with the B200 so, instead of profile comparisons, extinctions were compared along coincident flight tracks at the altitude of the G-1. The data were screened for coincidence as defined by a horizontal flight track separation of less than $5 \mathrm{~km}$ and a temporal separation of less than $30 \mathrm{~min}$. A total of five flights contained coincident data meeting this criteria: 3 March, 6 March, 9 March (two flights), and 15 March 2006.

The G-1 nephelometer and PSAP instruments used in this comparison are described in Sect. 2 above. The scattering coefficients were corrected to ambient relative humidity with Eq. (3) (assuming a dry RH of 30\%) and $\gamma$ value of 0.49 due to the fact that all of these measurements were acquired at altitudes greater than $2 \mathrm{~km}$ above sea level. Additionally, the absorption coefficients are corrected for scattering (Bond et al., 1999, Eq. 1, Table 4). As mentioned in Sect. 2, the nephelometer scattering and PSAP absorption were scaled to $532 \mathrm{~nm}$ (assuming an Angstrom coefficient of unity) and summed to derive extinction.

Figure 11 shows a summary of all coincident HSRL and G-1 $532 \mathrm{~nm}$ extinction data where the HSRL extinctions were averaged over four vertical sampling bins (a total of $120 \mathrm{~m}$ ) centered on the G-1 altitude. The HSRL and G1 extinctions are in good agreement over a wide range of aerosol extinctions (from $\sim 0 \mathrm{~km}^{-1}$ to $0.4 \mathrm{~km}^{-1}$ ), which includes significantly larger values than those observed in the coincident AATS-14 and HiGEAR observations discussed above. Even with the large range of extinction values, the bias difference of HSRL and the G-1 extinction is still low $-0.00032 \mathrm{~km}^{-1}$, or $-0.27 \%$, (HSRL lower) with good correlation. The complete set of regression statistics are summarized in Table 2. The spread in the scatter plot is likely due to horizontal and temporal sampling differences (e.g., advection of horizontally varying aerosols over the time lag between the two measurements as observed in the HiGEAR case above). In Fig. 11 the red filled circles are points for which the relative humidity was less than $65 \%$. For cases with higher than $65 \%$ relative humidity more than a $30 \%$ enhancement was added to the scattering coefficient, computed from Eq. (3). Neglecting points with $\mathrm{RH}>65 \%$ yields a bias of $0.0031 \mathrm{~km}^{-1}$ (2.9\%, HSRL higher). Table 3 shows the regression results for low relative humidity. The regression was also performed with the inclusion of relative humidity between $65 \%$ and $100 \%$ to test the humidity correction, where the bias difference, rms difference, and slope were found to vary within the range the values reported in Tables 2 and 3 . This implies that the bias difference was overall small and slightly positive and the slope was overall slightly larger than unity for all relative humidities. This discrepancy could be due to many factors, though it is possibly due to the application of a single parameterization for the relative humidity correction applied to all of the G-1 data, which was over several days and many air masses. Still, the results show that the extinction from HSRL and the in-situ measurements on the G-1 are in very good agreement.

\subsection{AERONET}

The AERONET (Holben et al., 1998) deployed automatic tracking sun and sky scanning radiometers to several stations in and around Mexico City: Orizaba (19.106 N, 97.324 W), Mexico City (19.334 N, 99.182 W), Tamihua $(21.261 \mathrm{~N}$, 97.442 W), and Veracruz (19.14 N, 96.187 W), and heavily instrumented sites designated as T0 at the Instituto Mexicano del Petróleo $(19.490 \mathrm{~N}, 99.148 \mathrm{~W}), \mathrm{T} 1$ at the Universidad Tecnológia del Tecámac (19.703 N, 98.982 W), and T2 at the Rancho La Bisnaga $(20.010 \mathrm{~N}, 98.909 \mathrm{~W})$. At the time of this work level 2 AERONET data existed for only Mexico City, T0, T1, and Tamihua so Level 1.5 data were used for Orizaba and T2. The HSRL optical depths were compared 


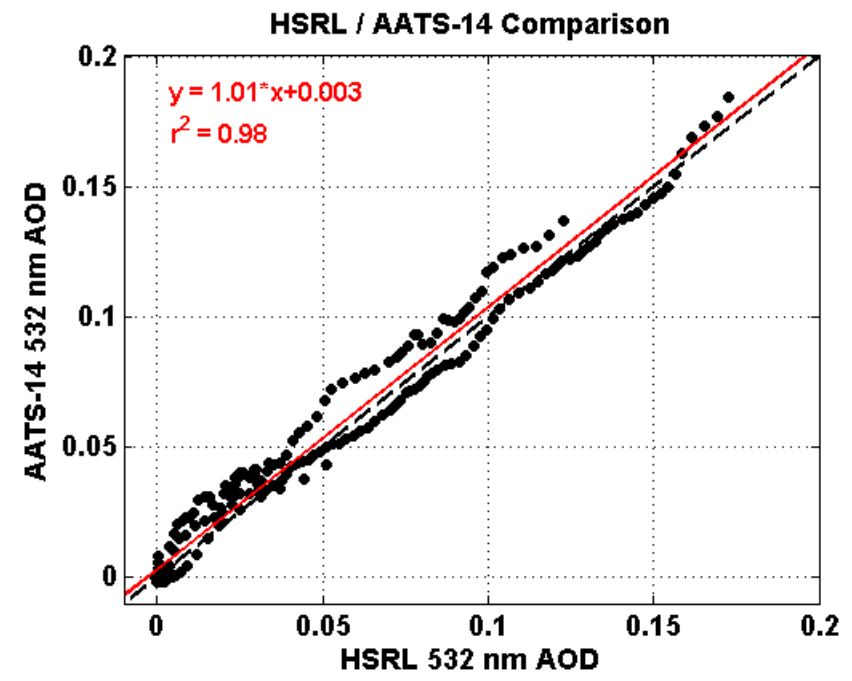

Fig. 10. Comparison of $532 \mathrm{~nm}$ AOD from HSRL and AATS-14 for all three profiles acquired on 10 March, 12 March, and 15 March 2006 with the bilinear regression in red and the one to one line in black (dashed).

to the AERONET $500 \mathrm{~nm}$ optical depths, scaled to $532 \mathrm{~nm}$ with wavelength using the AERONET derived $500 \mathrm{~nm}$ to $870 \mathrm{~nm}$ angstrom coefficient. Using the criterion of limiting temporal coincidence to within a one hour window between the HSRL and AERONET optical depth measurements and a $10 \mathrm{~km}$ spatial distance between the site and the HSRL flight track, 10 coincident observations were found. All AOD measurements falling within the spatial/temporal window were averaged and are summarized in Fig. 12.

The $532 \mathrm{~nm}$ optical depth bias difference was -0.005 (HSRL lower), or $-1.8 \%$, and the complete regression results are shown in Table 2. Some of this discrepancy may be accounted for by any aerosol optical depth above the sampling range of the airborne HSRL, which is typically from the surface to $6.5 \mathrm{~km}$ above mean sea level for the extinction and AOD measurement (the aircraft altitude is typically $\sim 9 \mathrm{~km}$ and the nearest $2.5 \mathrm{~km}$ of the profile are conservatively excluded from the extinction and optical depth calculation due to incomplete transmitter-receiver overlap). The stratospheric optical depth is estimated to be 0.005 for midlatitudes in the Northern Hemisphere (Jäger, 2005), however this does not account for aerosol between the tropopause and the HSRL measurement. In order to estimate the amount of AOD above HSRL's measurement all of the AATS-14 data were examined for optical depths at altitudes greater than $6 \mathrm{~km}$. Three dates were found to meet these criteria: 6,15 , 19 March 2006, with the average J-31 altitude of $6.3 \mathrm{~km}$. The average $532 \mathrm{~nm}$ optical depth above $6.3 \mathrm{~km}$ as determined from the AATS-14 measurements was $0.011 \pm 0.002$, which is larger than the 0.005 bias between the near-coincident AERONET and HSRL AOD measurements. This discrepancy is likely due to small fluctuations of AOD in the upper

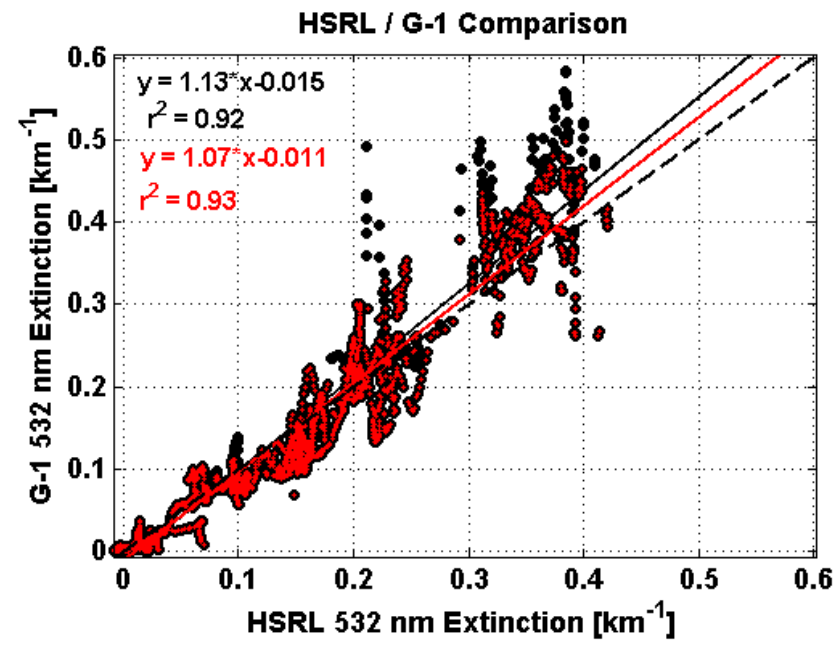

Fig. 11. A comparison of all coincident HSRL and G1 extinction data (black circles) within $5 \mathrm{~km}$ and $\pm 30 \mathrm{~min}$. The red filled smaller circles indicate data points with relative humidity less than $65 \%$. Black and red lines indicate the bilinear fit of the data with all points considered and with only points with associated relative humidity less than $65 \%$, respectively.

troposphere as well as the relatively few data points in both the HSRL/AERONET comparison and the estimation of optical depth above HSRL using the AATS-14 data. Another potential source of error in the HSRL AOD is from the surface to $150 \mathrm{~m}$ above the surface extrapolation to avoid ground contamination of the HSRL signal. This extrapolation could result in small AOD errors for cases where there is a strong gradient in aerosol near the surface.

Differences on the order of 0.005 can easily be accounted for by the aerosols above HSRL or near the ground and Ferrare et al. (2006) found similar biases with a ground based Raman lidar and sunphotometer measurements. More data points are required to make any statistical statements about the AOD comparison; this analysis will be done in the future using data from numerous HSRL airborne campaigns conducted after MILAGRO. While more data would be useful, we note that the near-coincident HSRL-AERONET observations from MILAGRO are within the accuracy range comparison of AATS-14 to ground based sun photometer measurements of $\sim 5 \%$ in a recent field study.

\subsection{Discussion of HSRL validation and comparison with previous studies}

The HSRL $532 \mathrm{~nm}$ aerosol extinction profiles are, generally, in excellent agreement with three separate measurements: AATS-14, HiGEAR, and the extinction measurements from the G-1. Schmid et al. (2006) found in a comparison of ten lidars that there was often little bias between lidar extinctions and AATS-14 at $532 \mathrm{~nm}$, though when a bias was present it was positive, while our study found a small negative bias 


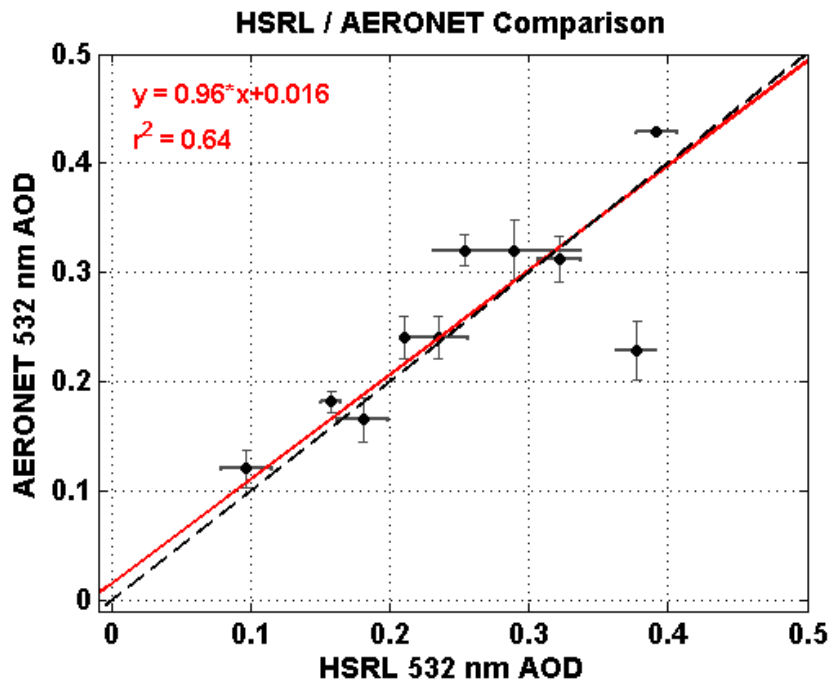

Fig. 12. Comparison of mean $532 \mathrm{~nm}$ AOD from HSRL and AERONET (all stations) using $1 \mathrm{~h}$ and $10 \mathrm{~km}$ as the criteria for coincidence. The error bars represent the standard deviation of the data points falling within the coincidence criteria frame. The black dashed line is the one to one line and the red line is the bilinear regression.

of $-0.00029 \mathrm{~km}^{-1}(-0.96 \%)$. It should be noted that in the Schmid et al. (2006) study, of the ten lidar comparisons presented, eight were against elastic lidars which cannot directly measure aerosol extinction and the two Raman lidars comparisons were at $355 \mathrm{~nm}$; the subject of this paper is the first comparison between AATS-14 and a lidar measuring the aerosol extinction coefficient at $532 \mathrm{~nm}$.

Bias differences in previous studies found that lidars generally yield larger extinction measurements than in-situ techniques. We found the HSRL extinctions compared to two in-situ techniques to have a small negative (HSRL lower) bias. Bias difference between HSRL and the in-situ techniques can be due to sampling differences due to gradients, inlet sampling cutoff causing the in-situ to miss some coarse mode, or the humidity correction to aerosol scattering. The inlet sampling cutoff would result in a positive bias, so it was not likely a factor in this study. For the in-situ measurements onboard the C-130 (HiGEAR), we found little difference in bias and regression slope when removing high relative humidity points to test the RH correction applied to the dataset. Removing the high humidity data from the G-1 in-situ comparison led to slopes slightly smaller (but larger than unity) and larger bias values, indicating that the simple humidity correction used on the G-1 scattering may not be applicable in all situations.

We note that the extinction differences in the comparisons presented in this study are approximately consistent with the typical differences of $15-20 \%$ between state-of-the-art instruments in measuring ambient aerosol extinction at visible wavelengths (Schmid, et al., 2006). The differential and col- umn aerosol optical depth comparison presented here is also a direct validation of the HSRL AOD products. The HSRL column $532 \mathrm{~nm}$ AOD values are 0.015 lower than AERONET which is likely due to AOD above the region where HSRL measurement are retrieved from the aircraft $(\sim 6 \mathrm{~km})$.

\section{Summary}

We have presented NASA LaRC airborne HSRL measurements of aerosol backscatter, extinction, and depolarization at two wavelengths $(532 \mathrm{~nm}$ and $1064 \mathrm{~nm})$ and aerosol optical depth at $532 \mathrm{~nm}$ acquired during the MILAGRO field campaign. The measurements from the 9 March flight were shown to illustrate the value of the data in providing vertical context for the in situ measurements acquired on the DOE G-1 aircraft and inferring aerosol type. Similarly, the data from the 29 March flight were shown to provide information on vertical and horizontal aerosol gradients useful for interpretation of the in situ aerosol data acquired on the NSF/NCAR C-130. The MILAGRO campaign also provided an excellent first opportunity to validate the HSRL extinction measurements. Coordinated flights with the NASA J-31 and NSF/NCAR C-130 allowed us to compare eight vertical profiles of extinction derived from instrumentation employing vastly different techniques to the HSRL extinction profiles. The HSRL $532 \mathrm{~nm}$ extinction profile measurements were in excellent agreement (differences less than $0.001 \mathrm{~km}^{-1}$ ) with the AATS-14 and HiGEAR instruments, proving the accuracy of the HSRL technique, and the LaRC HSRL instrument in particular, for measuring aerosol extinction. Overall, the extinction and AOD bias differences were less than $6 \%$ at $532 \mathrm{~nm}$ and are summarized in Tables 2 and 3 .

Acknowledgements. We gratefully acknowledge the NASA Langley Flight Research Service Directorate for their support of B200 flight operations during MILAGRO. We would also like to thank all of the aircraft crews and personnel of the G-1, J-31, and C-130 for making this mission possible. Support for the HSRL deployment during MILAGRO and the analyses of these data was provided by the NASA Science Mission Directorate, the NASA CALIPSO project, and the Office of Science (BER), US Department of Energy (Atmospheric Science Program), Interagency Agreement No. DE-AI02-05ER6398. We also acknowledge Edward T. Peltzer, MBARI, for the bilinear regression code.

Edited by: J. Gaffney

\section{References}

Bond, T. C., Anderson, T. L., and Campbell, D.: Calibration and intercomparison of filter-based measurements of visible light absorption by aerosols, Aerosol Sci. Technol., 30, 582-600, 1999.

Charlson, R. J., Schwartz, S. E., Hales, J. M., Cess, R. D., Coakley, J. A., Hansen, J. E., and Hofmann, D. J.: Climate forcing by anthropogenic aerosols, Science, 255, 423-430, 1992. 
Cattrall, C., Reagan, J., Thome, K., and Dubovik, O.: Variability of aerosol and spectral lidar and backscatter and extinction ratios of key aerosol types derived from selected Aerosol Robotic Network locations, J. Geophys. Res., 110, D10S11, doi:10.1029/2004JD005124, 2005.

Chudamani, S., Spinhirne, J. D., and Clarke, A. D.: Lidar aerosol backscatter cross sections in the $2-\mu \mathrm{m}$ near-infrared wavelength region, Appl. Optics, 35, 4812-4819, 1996.

Fast, J. D., de Foy, B., Acevedo Rosas, F., Caetano, E., Carmichael, G., Emmons, L., McKenna, D., Mena, M., Skamarock, W., Tie, X., Coulter, R. L., Barnard, J. C., Wiedinmyer, C., and Madronich, S.: A meteorological overview of the MILAGRO field campaigns, Atmos. Chem. Phys., 7, 2233-2257, 2007, http://www.atmos-chem-phys.net/7/2233/2007/.

Fernald, F. G.: Analysis of Atmospheric Lidar Observations: Some Comments, Appl. Optics, 23, 652-653, 1984.

Ferrare, R., Turner, D., Clayton, M., Schmid, B., Redemann, J., Covert, D., Elleman, R., Ogren, J., Andrews, E., Goldsmith, J., and Jonsson, H.: Evaluation of daytime measurements of aerosols and water vapor made by an operational Raman lidar over the Southern Great Plains, J. Geophys. Res., 111, D05S08, doi:10.1029/2005JD005836, 2006.

Grell, G. A., Peckham, S. E., Schmitz, R., McKeen, S. A., Frost, G., Skamarock, W. C., and Eder, B.: Fully coupled "online" chemistry within the WRF model, Atmos. Environ., 39, 6957-6975, 2005.

Hair, J. W., Caldwell, L. M., Krueger, D. A., and She, C. Y.: High-spectral-resolution lidar with iodine-vapor filters: measurement of atmospheric-state and aerosol profiles, Appl. Optics, 40, 5280-5294, 2001.

Hair, J. W., Hostetler, C. A., Cook, A. L., Harper, D. B., Ferrare, R. A., Mack, T. L., Welch, W., Isquierdo, L. R., and Hovis, F. E.: Airborne High Spectral Resolution Lidar for Profiling Aerosol Optical Properties, Appl. Optics, 47(36), 6734-6752, doi:10.1364/AO.47.006734, 2008.

Haywood, J. M., Ramaswamy, V., and Donner, L. J.: A limitedarea-model case study of the effects of sub-grid scale variations in relative humidity and cloud upon the direct radiative forcing of sulfate aerosol, Geophys. Res. Lett., 24, 143-146, 1997.

Holben, B. N., Eck, T. F., Slutsker, I., Tanré, D., Buis, J. P., Setzer, A., Vermote, E., Reagan, J. A., Kaufman, Y. J., Nakajima, T., Lavenu, F., Jankowiak, I., and Smirnov, A.: AERONET-A federated instrument network and data archive for aerosol characterization, Rem. Sens. Environ., 66, 1-16, 1998.

Jäger, H.: Long-term record of lidar observations of the stratospheric aerosol layer at Garmisch-Partenkirchen, J. Geophys. Res., 110, D08106, doi:10.1029/2004JD005506, 2005.

Kasten, F.: Visibility in the prephase of condensation, Tellus, 21, 631-635, 1969.

Liu, Z., Hunt, W., Vaughan, M., Hostetler, C., McGill, M., Powell, K., Winker, D., and Hu, Y.: Estimating random errors due to shot noise in backscatter lidar observations, Appl. Optics, 45, 44374447, 2006.

Livingston, J. M., Redemann, J., Russell, P. B., Torres, O., Veihelmann, B., Veefkind, P., Braak, R., Smirnov, A., Remer, L., Bergstrom, R. W., Coddington, O., Schmidt, K. S., Pilewskie, P., Johnson, R., and Zhang, Q.: Comparison of aerosol optical depths from the Ozone Monitoring Instrument (OMI) on Aura with results from airborne sunphotometry, other space and ground measurements during MILAGRO/INTEX-B, Atmos. Chem. Phys. Discuss., 9, 9961-10013, 2009,

http://www.atmos-chem-phys-discuss.net/9/9961/2009/.

McGill, M. J., Hlavka, D. L., Hart, W. D., Welton, E. J., and Campbell J. R.: Airborne lidar measurements of aerosol optical properties during SAFARI-2000, J. Geophys. Res., 108(D13), 8493, doi:10.1029/2002JD002370, 2003.

McNaughton, C. S., Clarke, A. D., Kapustin, V., Shinozuka, Y., Howell, S. G., Anderson, B. E., Winstead, E., Dibb, J., Scheuer, E., Cohen, R. C., Wooldridge, P., Perring, A., Huey, L. G., Kim, S., Jimenez, J. L., Dunlea, E. J., DeCarlo, P. F., Wennberg, P. O., Crounse, J. D., Weinheimer, A. J., and Flocke, F.: Observations of heterogeneous reactions between Asian pollution and mineral dust over the Eastern North Pacific during INTEX-B, Atmos. Chem. Phys. Discuss., 9, 8469-8539, 2009, http://www.atmos-chem-phys-discuss.net/9/8469/2009/.

Molina, L. T., Madronich, S., Gaffney, J., et al.: An Overview of MILAGRO 2006 Campaign: Mexico City Emissions and its Transport and Transformation, Atmos. Chem. Phys. Discuss., in preparation, 2009.

Piironen, P. and Eloranta, E. W.: Demonstration of a high-spectralresolution lidar based on an iodine absorption filter, Opt. Lett., 19, 234-236, 1994.

Redemann, J., Masonis, S. J., Schmid, B., Anderson, T. L., Russell, P. B., Livingston, J. M., Dubovik, O., and Clarke, A. D.: Clear-column closure studies of aerosols and water vapor aboard the NCAR C-130 during ACE-Asia, 2001, J. Geophys. Res., 108(D23), 8655, doi:10.1029/2003JD003442, 2003.

Russell, P. B., Livingston, J. M., Redemann, J., Schmid, B., Ramirez, S., Eilers, S. A., Kahn, R., Chu, A., Remer, L., Quinn, P. K., Rood, M. J., and Wang, W.: Multi-gridcell validation of satellite aerosol property retrievals in INTEX/ITCT/ICARTT 2004, J. Geophys. Res., 112, D12S09, doi:10.1029/2006JD007606, 2007.

Satheesh, S. K.: Letter to the Editor: Aerosol radiative forcing over land: effect of surface and cloud reflection, Ann. Geophys., 20, 2105-2109, 2002, http://www.ann-geophys.net/20/2105/2002/.

Schmid, B., Hegg, D. A., Wang, J., Bates, D., Redemann, J., Russell, P. B., Livingston, J. M., Jonsson, H. H., Welton, E. J., Seinfeld, J. H., Flagan, R. C., Covert, D. S., Dubovik, O., and Jefferson, A.: Column closure studies of lower tropospheric aerosol and water vapor during ACE-Asia using airborne Sun photometer and airborne in situ and ship-based lidar measurements, J. Geophys. Res., 108(D23), 8656, doi:10.1029/2002JD003361, 2003.

Schmid, B., Ferrare, R., Flynn, C., Elleman, R., Covert, D., Strawa, A., Welton, E., Turner, D., Jonsson, H., Redemann, J., Eilers, J., Ricci, K., Hallar, A. G., Clayton, M., Michalsky, J., Smirnov, A., Holben, B., and Barnard, J.: How well do state-ofthe-art techniques measuring the vertical profile of tropospheric aerosol extinction compare?, J. Geophys. Res., 111, D05S07, doi:10.1029/2005JD005837, 2006.

Sprent, P. and Dolby, G.: The geometric mean functional relationship, Biometrics, 36, 547-550, 1980.

Solomon, S., Qin, D., Manning, M., Chen, Z., Marquis, M., Averyt, K. B., Tignor, M., and Miller, H. L. (Eds.): Climate Change 2007: The Physical Science Basis. Contribution of Working Group I to the Fourth Assessment Report of the Intergovernmental Panel on Climate Change (IPCC, 2007) Cambridge University 
Press, Cambridge, United Kingdom and New York, NY, USA, 2007.

Sugimoto, N. and Lee, C. H.: Characteristics of dust aerosols inferred from lidar depolarization measurements at two wavelengths, Appl. Optics, 45, 7468-7474, 2006.

Torres, O., Bhartia, P. K., Herman, J. R., Ahmad, Z., and Gleason, J.: Derivation of aerosol properties from satellite measurements of backscattered ultraviolet radiation: Theoretical basis, J. Geophys. Res., 103(D14), 17099-17110, 1998.
Virkkula, A., Ahlquist, N. C., Covert, D. S., Arnott, W. P., Sheridan, P. J., Quinn, P. K., and Coffman, D. J.: Modification, Calibration and a Field Test of an Instrument for Measuring Light Absorption by Particles, Aerosol Sci. Technol., 39, 68-83, doi:10.1080/027868290901963, 2005. 